$\mathbf{R}_{\text {ESEARCH }} \mathbf{P}_{\text {APER }} \longrightarrow \frac{\text { FOOD SCIENCE }}{\text { RESEARCH JOURAL }}$

e ISSN-2230-9403 — Visit us : www. researchjournal.co.in Volume 9 | Issue 1 | April, 2018 | 138-142 DOI : 10.15740/HAS/FSRJ/9.1/138-142

\title{
Reduction of anti nutritional factors in differently processed supplementary soya products
}

\begin{abstract}
N.S. Ghatge
Soyabean content different anti nutritional factors such as phytate phosphorus, trypsin inhibitor activity, tannin, acid detergent fibres, lignin and cellulose. These antinutritional factors reduced by using various processing techniques like roasting, soaking, frying autoclaving, boiling etc. Soya products such as Soyaladoo, soyachakkali and soyaflakes chiwada were formulated by standard method and analyzed for its ant nutritional factors from raw material as well as finished products Soyaladoo, soyachakali and soyaflakes chiwada. The significant reuction in phytate phosphorus, trypsin inhibitor activity, tannin, acid detergent fibres, lignin and cellulose seen in Soyaladoo, soyachakkali and soyaflakes chiwada, respectively.
\end{abstract}

Key Words : Soyladoo, Soyachakali, Soayflakes chiwada

How to cite this article :, Ghatge, N.S. (2018). Reduction of anti nutritional factors in differently processed supplementary soya products. Food Sci. Res. J., 9(1): 138-142, DOI : 10.15740/HAS/FSRJ/9.1/138-142.

\footnotetext{
N.S. Ghatge, Alfa Social and Education Foundation's Dhanwantary Arts and Science College, Dhawalpuri, Parner, Ahmednagar (M.S.) India (Email : nalinihemangi26@ rediffmail.com)
} 